\title{
DIREITO, IGUALDADE E ALTERIDADE COMO ELEMENTOS DA JUSTIÇA EM TOMÁS DE AQUINO
}

\author{
RIGHT, EQUALTY AND ALTERITY AS ELEMENTS OF JUSTICE IN THOMAS AQUINAS
}

Yuri Ikeda Fonseca*

\section{RESUMO}

Este artigo pretende abordar o pensamento de Santo Tomás de Aquino acerca da justiça, com base principalmente nas questões 57 e 58 da Segunda Parte da Segunda Parte da Suma Teológica, tendo por hipótese a ideia de que o direito, a igualdade e a alteridade são elementos constitutivos da justiça tomista. $\mathrm{O}$ artigo trata, inicialmente, da proposição tomista de que o direito é objeto da justiça, e investiga o significado da palavra direito (ius) em Aquino como um justo agir direcionado a outra pessoa segundo uma medida de igualdade. Trata, em seguida, da igualdade como medida do justo, e expõe o conceito de justiça formulado por ele, sendo ela uma disposição de destinar a cada um o que lhe é devido. Apresenta, então, as duas acepções de "outro" apontadas por Aquino, com a ressalva de que essa duplicidade não é mais aplicável à atualidade, e por fim aborda os argumentos de Aquino para demonstrar que a justiça é algo necessariamente para o outro, apontando, ainda, que a justiça tomista é fundamentada no princípio do amor ao próximo.

PALAVRAS-CHAVE: Tomás de Aquino. Justiça. Direito. Igualdade. Alteridade.

\section{ABSTRACT}

This paper intends to approach Saint Thomas Aquinas' thought concerning justice, based mainly on the questions 57 and 58 of the Second Part of the Second Part of the Summa Theologiae, having as its hypothesis the idea that right, equality and alterity are constitutive elements of Thomistic justice. The paper approaches, initially, the Thomistic proposition that right is the object of justice, and investigates the meaning of the word right (ius) in Aquinas. It then treats equality as the measure of the just, and exposes the concept of justice formulated by Aquinas, as being a disposition of rendering to each one his due. It presents, then, the two acceptations of "other" pointed by Aquinas, excepting that this duplicity is no longer applicable nowadays, and lastly it approaches Aquinas' arguments to demonstrate that justice is something necessarily towards another, also pointing that the Thomistic justice is founded on the principle of love of our neighbor.

KEYWORDS: Thomas Aquinas. Justice. Right. Equality. Alterity.

\section{INTRODUÇÃO:}

\section{TOMÁS DE AQUINO E O DEBATE JURÍDICO-POLÍTICO CONTEMPORÂNEO}

A teoria do direito contemporânea apresenta uma ampla abertura para os debates da filosofia moral, e de fato deles não prescinde. A hegemonia do positivismo jurídico, calcado na tese da separação entre o direito e a moral, foi contestada fortemente a partir da segunda

\footnotetext{
* Mestre em Direito pela Universidade Federal do Pará. E-mail: yikedaf@ yahoo.com.br.
} 
metade do século XX, em especial pelas visões que se convencionou chamar de póspositivistas, relacionadas a autores como Ronald Dworkin e Robert Alexy, e em um outro caminho, bastante diverso nas premissas teóricas, pela nova teoria do direito natural, cujas figuras centrais são Germain Grisez, John Finnis e Joseph Boyle. Essas duas visões distintas têm em comum o fato de serem ligadas a uma revitalização das discussões sobre fins e valores no direito.

A multimilenar tradição do direito natural, iniciada durante a antiguidade clássica nos pensamentos de filósofos como Heráclito, Aristóteles e Cícero, atingiu um de seus pontos paradigmáticos na obra de Santo Tomás de Aquino (1224/1225-1274). Nos tempos atuais, a chamada teoria neoclássica (ou nova teoria) do direito natural baseia-se em uma retomada do pensamento ético da filosofia aristotélico-tomista com ênfase na noção de razão prática.

Conforme aponta Bárbara Alencar Ferreira Lessa (2013), a redescoberta da filosofia de Tomás de Aquino na idade contemporânea iniciou-se em 1879, com a publicação da encíclica Aeterni Patris do Papa Leão XIII (1879), que incentivava uma nova leitura de Santo Tomás. Dentre os pensadores vinculados à retomada tomista com influência na filosofia do direito, é possível destacar autores como Jacques Maritain, Michel Villey e Javier Hervada.

Quanto à nova teoria do direito natural, ela teve seu início no artigo First principle of practical reason, de Germain Grisez (1965). Nesse estudo, Grisez interpreta e discute o significado do primeiro princípio da razão prática, que é também o primeiro preceito da lei natural, "o bem é de ser feito e perseguido, e o mal é de ser evitado", na formulação de Aquino. Nesse artigo, Grisez apresenta a tese segundo a qual a razão prática reconhece bens humanos fundamentais.

Uma obra central dessa abordagem do direito natural é o livro Lei natural e direitos naturais, de John Finnis (2011), para quem os princípios da lei natural - os quais são um conjunto de padrões morais gerais formulados a partir da conjugação entre os princípios que informam os bens básicos e os requisitos da razoabilidade prática (tais como possuir um plano coerente de vida e não ter preferências arbitrárias entre valores e pessoas) que distinguem o correto pensamento prático do incorreto - justificam o exercício da autoridade na comunidade e, assim, explicam a força obrigatória das leis positivas, as quais são defeituosas quando em desconformidade com esses princípios.

Partindo de sua base aristotélico-tomista, a nova teoria do direito natural volta-se fortemente à ideia de bem comum, tido como um dos fins precípuos do direito. Nessa 
concepção teleológica do mundo e das instituições, o bem comum é um importante parâmetro para a identificação de direitos.

Diante desse cenário, nota-se que a filosofia de Tomás de Aquino se encontra plenamente integrada ao debate jurídico contemporâneo. Não somente a este, mas também o pensamento tomista se tornou uma parte relevante das filosofias moral e política contemporâneas por meio dos trabalhos de autores como Elizabeth Anscombe e Alasdair MacIntyre. Anthony J. Lisska (2015, p. 308-309) aponta que a retomada da ética das virtudes na segunda metade do século XX colocou a teoria moral de Aquino, baseada na ética aristotélica, em um ponto central das discussões, particularmente para oferecer respostas às teses segundo as quais não existe possibilidade de realizar investigações racionais verdadeiras sobre temas da ética.

De acordo com Luis Fernando Barzotto (2010), a dogmática jurídica contemporânea é paralela a uma radicalização do individualismo, e nela o direito é pensado como uma qualidade inerente ao indivíduo e anterior a qualquer relação social, diferentemente da concepção clássica, inclusive aquela do direito romano e de Tomás de Aquino, segundo a qual o direito é uma relação com os outros, noção que pretendemos abordar como tema central do presente estudo.

Embora não adiramos filosoficamente ao jusnaturalismo tomista, por não compartilharmos de alguns pressupostos essenciais dessa linha de pensamento, em especial sua base teológica ${ }^{1}$, entendemos que a teoria da justiça de Tomás de Aquino, a qual remete a Aristóteles e ao direito romano, possui interessantes argumentos para alguns temas pontuais do direito contemporâneo no sentido de explicar o fenômeno jurídico e seus fundamentos e atributos, propiciando reflexões nesse sentido, mesmo para quem não se filia à tradição da lei natural no formato tomista ou outros. Dessa forma, concentraremos o presente estudo em um aspecto específico do pensamento de Aquino cujas reflexões independem da aceitação de uma revelação teológica específica, sendo fundamentadas em princípios que possuem ampla aceitação também no pensamento secular, por exemplo, a regra de ouro e a igualdade decorrente de uma natureza humana compartilhada (seja ela aceita como relacionada a uma

\footnotetext{
${ }^{1}$ Apesar de autores como Finnis (2011, p. 48-49) buscarem arguir uma defesa do jusnaturalismo de base tomista sem a necessidade de aceitação da existência de uma divindade nos moldes bíblicos, baseando-se especialmente na razão prática (onde residiria o natural da lei), a nosso ver, aderir ao tomismo desconsiderando pressupostos como a lei eterna (razão divina universal) e a lei divina (revelação) seria fazer uma ressalva grande demais para alguém se considerar de fato adepto dessa filosofia como um todo. Por outro lado, decerto não é imprescindível assumir esses pressupostos para subscrever o primeiro princípio da razão prática ou mesmo o ensinamento ético do amor ao próximo de Jesus de Nazaré, aos quais nos reportaremos como aspecto central do presente estudo.
} 
criação divina, como pretende Aquino, ou a elementos antropológicos, naturalísticos etc.), e cujas conclusões podem ser diretamente trazidas para a problemática do alegado individualismo da dogmática jurídica contemporânea: a ideia de essencial alteridade do direito e da justiça.

No tratamento do tema, apresentaremos inicialmente os conceitos de direito e de justiça em Aquino, apontando suas relações entre si e com a ideia de igualdade. Em seguida, abordaremos o tema propriamente dito da alteridade da justiça, e, por fim, a fundamentação desta naquilo que Tomás de Aquino considera o princípio basilar da alteridade, o amor ao próximo.

\section{OBJETO DA JUSTIÇA: O DIREITO OU JUSTO 1.1 O TERMO "IUS"}

Tomás de Aquino $^{2}$ trata especialmente acerca da justiça (iustitia) nas questões 58 e seguintes da Segunda Parte da Segunda Parte de sua Suma Teológica. No entanto, antes de adentrar o conteúdo da justiça, ele trata, na questão 57, acerca daquilo que considera ser o objeto da justiça: o direito (ius).

A preocupação de Aquino com o direito ocorre justamente por este ser objeto da virtude da justiça, e por ser esta uma das virtudes cardeais, em torno das quais todas as outras virtudes ordenam-se.

Na questão 57, artigo 1, Aquino já afirma a justiça como sendo uma virtude relacional. Enquanto outras virtudes - como a prudência e a temperança - aperfeiçoam o ser humano naquilo que convém a ele mesmo, a justiça ordena o ser humano naquilo que diz respeito não apenas a si, mas também aos outros. São chamadas de "ajustadas" (iustari) as coisas quando são igualadas a outras, e é considerado justo (iustum) aquilo que "em nosso agir" (in opere nostro $)^{3}$ corresponde com igualdade (aequalitas) a uma outra coisa - por exemplo, o pagamento em relação ao respectivo trabalho. Assim, a ação justa busca igualar duas coisas, e

\footnotetext{
${ }^{2}$ Para o texto original da Suma Teológica, ao qual nos reportamos ao citar os termos e passagens em latim e ao qual buscamos a fidelidade de tradução nas citações diretas, ver Tomás de Aquino (1888). Consultamos também a edição em língua inglesa (AQUINO, 1947). Nas citações da Suma, indicaremos apenas a questão e o artigo, entendendo-se todas da Segunda Parte da Segunda Parte, sendo indicada a parte somente quando a citação se referir a outra que não a II-II.

${ }^{3}$ Um dos possíveis significados para opus (obra, trabalho) é "ato", no sentido de realização de algo que está dentro das atribuições de uma pessoa (FARIA, 2003). Assim, optamos pela tradução de opus de maneira não literal como "o agir", nesse contexto. Como apontaremos adiante, a justiça para Aquino se realiza também a partir do actus.
} 
é chamado de justo "aquilo em que a ação de justiça se encerra" (ad quod terminatur actio iustitiae), como se o justo fosse algo portador da retidão da justiça. Diante disso se verifica que a justiça possui um objeto, isto é, o justo, que por sua vez equivale ao próprio direito.

Pode parecer evidente o bastante, pelo menos no latim, que o ius é o objeto da iustitia, como conclui Aquino (q. 57, a. 1). Porém, para sustentar essa conclusão, o autor precisou investigar e esclarecer o significado da palavra ius. Michel Villey (2014) observa que, no período de Tomás de Aquino, os sentidos dos termos fundamentais da ciência jurídica já se haviam tornado bastante nebulosos por conta do choque entre correntes adversárias. Aquino (q. 57, a. 1) argumenta que, tal como a palavra medicina originalmente significava o remédio usado para curar uma pessoa doente e depois passou a significar a arte pela qual esse procedimento é feito, a palavra direito era inicialmente usada para designar a própria coisa justa, passando depois a significar a arte de saber o que é justo, e posteriormente o local em que a justiça é aplicada (por exemplo, o tribunal), até que, por fim, passou a ser chamado de direito tudo aquilo que fosse determinado por uma autoridade competente para administrar a justiça, ainda que sua decisão fosse iníqua. Teria sido por conta dessa progressiva modificação semântica que a palavra direito se desvinculou do termo justiça, de que ele proveio. Não é difícil observar que esse último significado persiste até os dias atuais e ressoa nas situações em que se afirma que algo "é injusto, mas o direito permite".

No que concerne à terminologia na atualidade, observe-se que temos, na língua portuguesa, pelo menos três significados atribuíveis à palavra direito: o conjunto de normas que formam um determinado ordenamento jurídico ou o fenômeno jurídico como um todo, o que chamamos de direito objetivo; uma situação jurídica de alguém sob o amparo de uma norma, o que se denomina direito subjetivo; e ainda a ciência que se dedica ao estudo do direito objetivo e dos direitos subjetivos. Há certo costume de dizer e ensinar que o direito objetivo corresponde em latim à palavra lex (lei), e o direito subjetivo à palavra ius. Se em termos gerais essa afirmativa não é exata, no que concerne a Tomás de Aquino ela é de fato inaplicável. O ius tratado no presente estudo não remete absolutamente à noção de direito subjetivo, como pudemos verificar. Lisska (2015, p. 306-307) indica que Aquino não desenvolveu uma teoria de direitos individuais, e sua concepção de um direito natural (ius naturale) em contraposição ao direito positivo (ius positivum) não deve ser interpretada como equivalente às ideias moderna e contemporânea de direitos naturais, embora seja possível deduzir tais direitos de sua teoria, como o faz Finnis (1998; 2011), por exemplo. 
Tomás de Aquino (q. 57, a. 2) define o direito - ou, sinonimamente, o justo - como "um determinado agir (opus) ajustado com relação a outra pessoa segundo alguma medida de igualdade". Assim, o ius se refere a uma conduta ligada a uma relação objetiva entre pessoas.

Tal é a concepção aristotélico-tomista de direito como o justo subjetivo. Luis Fernando Barzotto (2010, p. 64) afirma que essa noção clássica de justiça pressupõe uma antropologia e uma sociologia específicas, em que se considera que a sociabilidade é elemento constitutivo da natureza humana, pois a pessoa humana é um ser relacional que só alcança sua plena realização em sociedade na qual todos tenham acesso a todos os bens necessários para tal.

\subsection{A IGUALDADE, MEDIDA DO JUSTO}

Conforme a definição acima citada, podemos considerar que Aquino reafirma que a alteridade é intrínseca à justiça. Além disso, ao se tratar de uma relação entre pessoas, a justiça requer a existência de uma igualdade (aequalitas) dentro dessa relação. Nesse sentido, a igualdade é o parâmetro essencial do justo, e a justiça pode ser vista como uma exigência da igualdade nas relações entre as pessoas. Abordaremos o entendimento acerca da igualdade em Aquino, por ser ela um requisito para que uma relação de alteridade possa ser qualificada como justa.

Ressalte-se que a aequalitas aqui referida não se trata de uma igualdade simples ou literal, mas de uma igualdade proporcional ou uma situação de paridade, em que as partes envolvidas, por assim dizer, "estão quites”. Michel Villey (2016, p. 56) observa que o termo aequum corresponde ao grego íson, que representa uma igualdade adaptada às qualidades das pessoas. Nesses termos, a partir da compreensão de Aristóteles, justiça é mensuração, equilíbrio. Com efeito, Aquino (q. 57, a. 4) afirma que o direito ou o justo é determinado por “comensuração para com o outro".

A aplicação da justa medida é um ditame da razão. Conforme a compreensão de Luis Fernando Barzotto (2010, p. 123), o ato próprio da razão humana - o juízo - consiste em identificar casos iguais e distinguir os desiguais, e o mundo é racionalizado a partir da utilização de uma regra ou medida comum capaz de estabelecer os parâmetros de igualdade e desigualdade entre os múltiplos e plurais objetos. A existência de uma relação jurídica não seria possível sem a igualdade fornecida pelo parâmetro comum da lei. Não há, portanto, o 
justo sem a igualdade. Para Tomás de Aquino (q. 57, a. 1), "a justiça requer a igualdade" (iustitia aequalitatem importat), razão pela qual a relação do ser humano com a lei divina não é de ius, e sim de fas (expressão da vontade divina), não havendo reciprocidade entre a divindade e os seres humanos, uma vez que, observa Aquino (q. 57, a. 1), "não podemos dar a Deus uma retribuição equivalente". Os seres humanos cumprem a lei divina na medida do possível e não totalmente, enquanto por outro lado a divindade cumpre a sua parte da relação por completo, não se configurando a equivalência que constitui a justiça. Barzotto (2010, p. 66) observa, ainda, que o paradigma de justiça da tradição clássica é a igualdade, e não a propriedade, como é característico das concepções modernas de direitos subjetivos.

\section{O CONCEITO DE JUSTIÇA EM AQUINO}

\subsection{JUSTIÇA E AÇÃO}

Diante do que foi até aqui abordado, a noção de ius em Aquino segue a noção de to díkaion (o justo) de Aristóteles. Tenha-se em mente que o adjetivo neutro díkaion (justo) precedido pelo artigo definido to pode ser utilizado como substantivo, de modo que to díkaion é entendido como "o que é justo" (MILLER, 1995, p. 97). Com base nessa forma, Michel Villey (2014, p. 115-116) é enfático no sentido de que esse neutro substantivado não significa a ação justa, tampouco o sujeito que pratica essa ação, mas simplesmente o objeto: essa "coisa justa", uma relação entre substâncias. O direito/justo é algo que está em nosso agir (in opere nostro), ou seja, na prática que se conforma ao que é justo, ao objeto da justiça (ius / to díkaion).

Recordemos que, como aponta Javier Hervada (2006, p. 33), para o pensamento tomista a razão opera de uma forma quando se trata de conhecer, sendo essa a forma da razão especulativa, e de uma outra forma quando se trata de agir, sendo essa a da razão prática, e é ao âmbito desta que o direito pertence. O justo não se trata, portanto, apenas de relações entre coisas, mas diz respeito também ao agir dentro de relações objetivas com os outros, as quais o direito regra.

\subsection{A JUSTIÇA COMO DISPOSIÇÃO DE DESTINAR A CADA UM O SEU DIREITO}

Ao interpretar a definição, atribuída a Ulpiano, segundo a qual justiça é "a vontade (voluntas) constante e perpétua que destina (tribuens) a cada um o seu direito", Aquino (q. 58, 
a. 1) a considera apropriada desde que ela seja entendida na forma correta, conforme veremos em seguida. Ele afirma que toda virtude é uma disposição (habitus) ${ }^{4}{ }^{5}$ que é princípio de um bom ato (actus), e dessa forma a virtude deve ser definida pelo bom ato acerca da própria matéria (circa propriam materiam) daquela virtude. O objeto da ação moral é a "matéria acerca da qual o ato se encerra" (materia circa quam terminatur actus) ${ }^{6}$, e ele determina o fim da vontade. A matéria acerca da qual está a justiça, conforme acima enunciado, é o direito/justo. A definição de Ulpiano, ao propor destinar a cada um o seu direito, delineia com precisão o ato da justiça e a sua respectiva materia circa quam, o direito.

Em Aristóteles, de acordo com Giovanni Reale (2015, p. 54), a matéria é potência, isto é, a capacidade de receber forma, tal como o bronze é potência para a estátua. Podemos então entender que o direito é potência para a justiça, que se realiza no ato jurídico (justo).

Para Tomás de Aquino (q. 58, a. 1), a definição de Ulpiano refere-se à vontade porque um ato só pode ser considerado virtuoso, seguindo o raciocínio de Aristóteles, caso ele seja voluntário, consistente e firme, daí a adequação da definição ao falar em uma "vontade constante e perpétua". Em seguida Aquino (q. 58, a. 1) ressalva que, embora seja essa uma definição completa de justiça, ela deveria mencionar não o ato, mas a disposição, que no ato se especifica. Feita essa observação, Aquino (q. 58, a. 1) profere o seu próprio conceito: “justiça é a disposição (habitus) segundo a qual alguém, por uma constante e perpétua vontade, destina a cada um o seu direito".

John Finnis (1998, p. 133) destaca que Aquino utiliza de forma inteiramente intercambiável as expressões "o que é seu" (quod suum est) e "seu direito" (ius suum), de modo que, quando Aquino afirma que o direito é o objeto da justiça, quer ele dizer que a justiça assegura o ius de outra pessoa, ou seja, aquilo que é dela ou a ela é devido como uma questão de igualdade.

\footnotetext{
${ }^{4} \mathrm{O}$ termo habitus é formado pelo verbo habeo ("eu tenho") mais o sufixo tus, formador do substantivo, e pode significar o estado de algo, ou uma atitude, postura, ou disposição do espírito (FARIA, 2003), o que inclui a disposição para agir de determinada forma. Assim, optamos por traduzir esse termo como "disposição" e não como literalmente "hábito", que traz antes a ideia de prática costumeira. Kathia Vieira Regina Bazuchi (2011, p. 19) conceitua habitus em Tomás de Aquino como a "perfeição que vem a ser uma espécie de disposição estável ou inclinação adquirida para um certo tipo de ato".

${ }^{5}$ Não confundir com o termo dispositio, utilizado por Aquino de forma mais próxima à ideia de diathesis em Aristóteles (2012, p. 158), referente ao "arranjo daquilo que possui partes, ou no que se refere ao espaço, à potência ou à forma", e que pode ser traduzido como "estado", embora também seja costumeiro traduzir como "disposição".

${ }^{6}$ No mesmo sentido, consta da Suma Teológica (I-II, q. 18, a. 2) que o objeto da ação é materia circa quam.
} 


\section{A ALTERIDADE DA JUSTIÇA \\ 3.1 DUAS ACEPÇÕES DE “OUTRO”}

Constatamos que a justiça, em Tomás de Aquino, consiste de algo que é para o outro (ad alterum), isto é, algo pertencente a uma relação de alteridade, pois a justiça é uma virtude que visa a um objeto exterior, e não somente ao aperfeiçoamento do próprio indivíduo que a pratica.

Anteriormente, mencionamos que o direito/justo envolve uma "comensuração para com o outro", na visão de Aquino (q. 57, a. 4). Uma vez que iremos, a seguir, tratar propriamente do tema da alteridade da justiça, cabe um apontamento sobre o significado de “outro", que para Tomás de Aquino possui uma dúplice acepção, que ele apresenta no artigo 4 da questão 57.

Há “o que simplesmente é outro" (quod simpliciter est alterum), ou seja, que é alguém distinto por completo, por exemplo, duas pessoas sem nenhuma relação de sujeição entre si (“unus non est sub altero"); entre estes há o que Aquino denomina "simplesmente justo". E, diversamente, há aquele que existe em relação ao outro sendo "quase dele" (quasi eius), no sentido de ser quase parte do outro, o que pode se configurar de diversas formas, desde a relação entre o escravo e o senhor até aquela entre o pai e o filho ou o marido e a esposa. Nesses casos, exemplifica Aquino (q. 57, a. 4), não se tem o "simplesmente justo", mas tipos específicos de justo, como o "justo dominativo" entre o escravo e o senhor, o "justo paterno" entre o pai e o filho e o "justo doméstico" entre o marido e a esposa.

Esses se tratam de casos em que a alteridade seria relativa, pois haveria uma certa dependência de um indivíduo em relação a um outro em algum aspecto relativo às coisas humanas ("in rebus humanis") (q. 57, a. 4), de modo que um indivíduo seria, nesse aspecto particular e nas situações dele decorrentes, uma extensão do outro. No que concerne à esposa em relação ao marido, Aquino procura esclarecer esse ponto utilizando-se de uma passagem da Epístola aos Efésios, 5, 28: "Assim os maridos devem amar as suas mulheres, como a seu próprio corpo. Quem ama a sua mulher, ama-se a si mesmo". Nessas situações, a alteridade é mitigada por uma espécie de confusão entre os indivíduos, decorrente de situações específicas de sujeição de um ao outro.

Diz Aquino (q. 57, a. 4) que “o filho, enquanto filho, é alguém do pai” (filius, inquantum filius, est aliquid patris), bem como o escravo, "enquanto escravo, é alguém do senhor", embora o filho ou o escravo, cada qual considerado enquanto homem (homo), seja 
alguém subsistente por si mesmo e distinto dos outros. Porque são subsistentes por si mesmos, pode-se falar em justiça para com eles; porém, se são alguém "de outro", nesse respeito não há que se falar em justiça desses outros em relação a eles. Lembrando-se que a justiça significa dar a cada um o que é seu; se o que pertence ao filho é também do pai, e o que pertence ao escravo é também do senhor, não há como haver justiça propriamente dita, o simplesmente justo. Se alguém dá a si mesmo aquilo que lhe é devido, isso não é considerado por Aquino como algo que se possa chamar estritamente de um ato justo.

Evidentemente, devemos entender essa posição de Aquino, que reproduz a de Aristóteles, com algumas necessárias ressalvas, visto que as relações sociais da atualidade são radicalmente diferentes dos contextos pré-modernos em que as concepções de justiça de Aristóteles e de Aquino foram desenvolvidas, pesando especialmente o fato de aqueles filósofos terem vivido em sociedades marcadamente hierárquicas ${ }^{7}$, enquanto a nossa é uma sociedade, em tese, igualitária. Conforme vimos, Aristóteles e Aquino trataram sobre a igualdade, mas em uma concepção pertinente ao modelo hierárquico das sociedades nas quais estavam inseridos. No contexto ocidental e contemporâneo, não apenas a escravidão e a servidão foram devidamente banidas do mundo institucional, como também soam particularmente mal ideias como a de que a esposa possa ser "quase do marido" em lugar de uma pessoa em plena igualdade dentro do contexto matrimonial e familiar. Ultrapassaria os limites do presente trabalho avaliar pormenorizadamente se as "alteridades mitigadas" e suas respectivas "justiças lato sensu" seriam aplicáveis às sociedades ocidentais atuais em algum aspecto, porém, supondo desde já que a resposta seja negativa, uma vez que estão excluídas as sujeições pessoais ("unus sub altero") que dariam causa a essa situação de alteridade específica, assumiremos que nos dias atuais, em sociedades democráticas, todas as relações de alteridade se caracterizam entre pessoas que são "simplesmente outros".

\subsection{A JUSTIÇA COMO NECESSARIAMENTE PARA O OUTRO}

É no artigo 2 da questão 58 da Segunda Parte da Segunda Parte que Tomás de Aquino diretamente discute se a justiça é, ou não, algo sempre para o outro (ad alterum).

\footnotetext{
${ }^{7}$ Paul E. Sigmund (2002 p. 325) nota que a teoria política de Tomás de Aquino combina visões tradicionais hierárquicas e feudais sobre a estrutura da sociedade com incipientes visões igualitárias e orientadas para a comunidade.
} 
Referimo-nos anteriormente à igualdade (aequalitas) como medida do direto/justo. Esse é um ponto fundamental da argumentação de Aquino para o seu posicionamento sobre a alteridade da justiça. Isso porque a igualdade pressupõe uma relação com outro indivíduo, uma vez que, para ser igual, é preciso ser igual a outra pessoa. Não é possível falar em igualdade com relação a si próprio, e sim com relação a outrem, necessariamente.

Ademais, a alteridade da justiça é um dos argumentos dispostos por Aquino (q. 58, a. 3) para responder à tese de que a justiça não seria uma virtude moral devido a ela ser algo externo, o que a classificaria não como algo relativo às atividades práticas (agibilia), mas às técnicas (factibilia). Para Aquino, essa opinião não se sustenta, pois, embora a justiça seja voltada a coisas exteriores, ela não se trata de fazer coisas, como é o caso da arte, e sim de utilizar as coisas no âmbito de nossas ações com relação aos outros.

Com efeito, Aquino (q. 58, a. 1) dispõe que a ordenação do ser humano, pela justiça, em suas relações com os outros pode ocorrer de duas formas: nas relações com os outros individualmente considerados, e nas relações com os outros em geral ("in communi”), na condição de alguém que serve à comunidade e, por conseguinte, a todos que pertencem à comunidade. Considerando que os indivíduos são parte de um todo - que é a comunidade -, o bem de uma parte é ordenável no bem do todo. A justiça, assim, ordena o ser humano para o bem comum. Como aponta Barzotto (2010, p. 65), na concepção aristotélico-tomista “a justiça encontra-se na intersecção entre Ética (bem da pessoa humana) e Política (bem comum)", e a teoria da justiça disciplina as relações entre pessoa e sociedade.

Tomás de Aquino (q. 58, a. 5) chama de "justiça legal” (iustitia legalis) essa que tem o bem comum como objeto próprio, e pela qual se determina aquilo que é devido à comunidade como um todo, ou devido aos outros na condição de membros da comunidade. O nome "legal" deriva do fato de que, para Aquino (I-II, q. 90, a. 2), a lei é ordenada precipuamente para o bem comum. Para Barzotto (2010, p. 66), o desenvolvimento dessa forma de justiça gerou o que entendemos hoje como "justiça social", ou seja, aquilo que estabelece o que é devido a todos os membros da sociedade, todos sujeitos absolutamente iguais em dignidade.

A justiça legal, para Aquino (q. 58, a. 7), ordena suficientemente o ser humano em suas relações com os outros. Ela o faz de forma imediata no que diz respeito ao bem comum, e de forma mediata quanto ao bem de outro indivíduo, sendo nesse caso necessária também a justiça particular. 


\subsection{ALTERIDADE E AMOR AO PRÓXIMO}

Antes de encerrar o presente trabalho, é necessário indicarmos, enfim, que a alteridade da justiça se relaciona diretamente com o princípio do amor ao próximo, que é seu fundamento. Trata-se, para Aquino (I-II, q. 100, a. 3) de um preceito primário, autoevidente à razão humana, do qual decorrem os preceitos secundários da lei natural. Pode-se dizer que o amor ao próximo é a nascente do vasto rio da ética tomista.

Cabe especificar o significado do termo "próximo" (proximus), que, embora também remeta à alteridade, não se confunde com o significado de "outro". O mandamento do amor ao próximo, como se sabe, baseia-se no Evangelho de Mateus, 22, 39, em que Jesus de Nazaré proferiu: “Amarás teu próximo como a ti mesmo". Aquino (q. 44, a. 7), interpretando essa passagem, entende que devemos amar os outros porque, como se pode inferir da própria terminologia, eles "são próximos de nós" (sunt nobis proximi) por compartilharem conosco uma natureza comum, a imagem e semelhança divinas. "Próximo" pode ser entendido como um sinônimo de "irmão" ou "amigo". Dessa forma, a "proximidade" existe em relação a todas as pessoas.

Independentemente da aceitação do pressuposto teológico da criação à imagem divina, também é possível receber o argumento de Aquino com base no compartilhamento de um mesmo conjunto de propriedades fundamentais comuns que constituem a essência humana, o que pode ser sustentado tanto por meio de explicações metafísicas quanto antropológicas ou naturalistas. Por isso Aquino (I-II, q. 100, a. 3) considera o princípio do amor ao próximo como autoevidente tanto pelo pressuposto da fé quanto pela natureza.

Barzotto (2010, p. 57) afirma que os ensinamentos de Jesus ocasionaram uma ética universalista da fraternidade, em que o "próximo" não mais se restringe aos membros do mesmo grupo ou comunidade, e amplia-se para todo ser humano. Desse modo, se todo humano é próximo, todas as pessoas são titulares de um dever de reciprocidade. A proximidade deixa de ser geográfica para basear-se na semelhança enquanto humanos, seres sociais que se realizam vivendo sua humanidade em comum e sendo devedores uns dos outros em termos éticos.

Ademais, para Tomás de Aquino (q. 44, a. 7), amar o próximo como a si mesmo não significa amar o outro literalmente de forma igual (aequaliter) a como alguém ama a si mesmo, mas de forma similar (similiter), isto é, desejando o bem do outro assim como deseja 
o próprio bem. A relação de alteridade, nesse sentido, deve ser pautada pela boa vontade para com o outro.

Conforme entende Finnis (1998), os deveres da justiça decorrem de um dever da virtude da amizade, expresso na chamada regra de ouro, que consiste em tratar os outros como se gostaria de ser por eles tratado. Tomás de Aquino (I-II, q. 99, a. 1) enuncia, citando Aristóteles, que a amizade que se tem para o outro vem da amizade que se tem para si mesmo. Como já observado, o "próximo" equivale ao "amigo", de modo que a regra de ouro é uma explicação do mandamento do amor ao próximo como a si mesmo. A regra da amizade, dessa forma, é a reciprocidade. Assim, também Barzotto (2017, p. 114) enuncia que o preceito do amor ao próximo se caracteriza por ser o princípio de todo e qualquer dever em relação ao próximo, e pode ser considerado como o fim para o qual tendem todos os demais preceitos morais. A própria regra de ouro seria um equivalente laico desse preceito, como Aquino (I-II, q. 99, a. 1) sugere ao afirmar que ela funciona como uma explicação da regra do amor ao próximo.

É dessa principiologia da amizade que decorre o dever de justiça, de destinar a cada um o que lhe é devido. Toda justiça depende de uma relação de alteridade em que se reconheça o outro como um próximo e se deseje para ele o bem de modo semelhante a como deseja o bem para si.

\section{CONCLUSÃO}

Justiça, para Tomás de Aquino, é uma disposição voluntária de destinar a cada um o seu direito/justo, em relações objetivas com outras pessoas nos parâmetros de uma medida de igualdade. Desse modo, verificamos que a justiça tomista possui como elementos o direito, a igualdade e a alteridade. O direito é o objeto da justiça, a igualdade é sua medida, e a alteridade é seu pressuposto.

O direito é sempre destinado ao outro, não sendo possível chamar de justiça se alguém destina a si mesmo o seu direito. Para haver igualdade, é necessário ser igual a outrem. A justiça, portanto, é necessariamente ad alterum, seja em relação aos outros individualmente caracterizando a justiça particular -, seja em relação aos outros enquanto membros da comunidade, configurando a justiça legal. 
O dever moral de realizar a justiça decorre, em última instância, do preceito prático do amor ao próximo, princípio fundamental da moral e pedra fundamental da moral em Tomás de Aquino, de modo que seu sistema ético repousa em uma ideia de alteridade.

\section{REFERÊNCIAS}

AQUINO, Tomás de. Summa Theologica. Nova York: Benziger Bros. 1947. Disponível em: http://www.documentacatholicaomnia.eu/03d/12251274,_Thomas_Aquinas,_Summa_Theolo giae_[2],_EN.pdf. Acesso em: 20 jan. 2017.

AQUINO, Tomás de. Summa Theologiae. Textum Leoninum Romae, 1888. Disponível em: http://www.corpusthomisticum.org/. Acesso em: 20 jan. 2017.

ARISTÓTELES. Metafísica. Tradução, textos adicionais e notas de Edson Bini. 2. ed. São Paulo: Edipro, 2012.

BARZOTTO, Luis Fernando. Teoria do direito. Porto Alegre: Livraria do Advogado, 2017.

BARZOTTO, Luis Fernando. Filosofia do direito: os conceitos fundamentais e a tradição jusnaturalista. Porto Alegre: Livraria do Advogado, 2010.

BAZUCHI, Kathia Regina Vieira. As virtudes cardeais em Tomás de Aquino. Dissertação (Mestrado em Filosofia). Universidade de Brasília, Brasília, 2011. Disponível em: http://repositorio.unb.br/bitstream/10482/8695/1/2011_KathiaReginaVieirBazuchi.pdf. Acesso em: 15 jan. 2017.

BÍBLIA. N. T. Epístola aos Efésios. In: Bíblia Sagrada. Edição Claretiana. São Paulo: Editora Ave-Maria, 2012.

FARIA, Ernesto. Dicionário latino-português. Belo Horizonte: Livraria Garnier, 2003.

FINNIS, John. Natural law and natural rights. 2. ed. Oxford: Oxford University Press, 2011.

FINNIS, John. Aquinas: moral, political and legal theory. Oxford: Oxford University Press, 1998.

GRISEZ, Germain. First principle of practical reason: a commentary on the Summa Theologiae, 1-2, Question 94, Article 2. Natural Law Forum, Paper 107, 1965.

HERVADA, Javier. Síntesis de historia de la ciencia del derecho natural. Pamplona: Ediciones Universidad de Navarra, 2006.

LEÃO XIII, Papa. Aeterni Patris: encyclical of Pope Leo XIII on the restoration of Christian philosophy. Disponível em: https://w2.vatican.va/content/leo- 
xiii/en/encyclicals/documents/hf_l-xiii_enc_04081879_aeterni-patris.html. Acesso em: 14 jan. 2017.

LESSA, Bárbara Alencar Ferreira. Natureza humana, direito e virtudes: uma interpretação da teoria do direito natural de Tomás de Aquino. Dissertação (Mestrado em Direito). Pontifícia Universidade Católica de Minas Gerais, Belo Horizonte, 2013.

LISSKA, Anthony J. The philosophy of law of Thomas Aquinas. In: MILLER Jr., Fred; BIONDI, Carrie-Ann (ed.). A treatise of legal philosophy and general jurisprudence, volume 6: a history of the philosophy of law from the Ancient Greeks to the scholastics. Second edition. Dordrecht, Heidelberg, London, New York: Springer, 2015. p. 285-310.

MILLER, Fred D. Nature, justice and rights in Aristotle's Politics. Oxford: Oxford University Press, 1995.

REALE, Giovanni. História da filosofia grega e romana, volume IV: Aristóteles. Tradução de Henrique Cláudio de Lima Vaz e Marcelo Perine. 3. ed. São Paulo: Loyola, 2015.

SIGMUND, Paul E. Law and Politics. In: DAVIES, Brian. Thomas Aquinas: Contemporary Philosophical Perspectives. New York: Oxford University Press, 2002, p. 325-337.

VILLEY, Michel. O direito e os direitos humanos. Tradução de Maria Ermantina de Almeida Prado Galvão. São Paulo: WMF Martins Fontes, 2016.

VILLEY, Michel. Questões de Tomás de Aquino sobre direito e política. Tradução de Ivone C. Benedetti. São Paulo: WMF Martins Fontes, 2014. 